\title{
Synthesis and electrical properties of $\mathrm{Ag}_{16} \mathrm{I}_{12} \mathrm{P}_{2} \mathrm{O}_{7}$
}

\author{
Artem Ulihin ${ }^{1^{-}}$, and Olga Protazanova ${ }^{2}$ \\ ${ }^{1}$ Institute of Solid State Chemistry and Mechanochemistry SB RAS, 630090, Kutateladze 18, Russia \\ ${ }^{2}$ Novosibirsk State University, 630090, Pirogova 2, Russia
}

\begin{abstract}
Superionic solid electrolyte $\operatorname{Ag}_{16} \mathrm{I}_{12} \mathrm{P}_{2} \mathrm{O}_{7}$ was prepared using solid state synthesis. The ionic conductivity of this compound was studied by the complex impedance spectroscopy method in a wide temperature range. It is shown that $\mathrm{Ag}_{16} \mathrm{I}_{12} \mathrm{P}_{2} \mathrm{O}_{7}$ is characterized by a high ionic conductivity at room temperature, comparable to the conductivity of liquid electrolytes.
\end{abstract}

\section{Introduction}

The detection and treatment of cardiovascular diseases is impossible without the use of modern methods of electrocardiography, electroencephalography and other methods of clinical monitoring and medical diagnostics [1]. The basic working elements in these methods are biosensors, which provide a high-quality and reliable primary electrical signal, which is fed further to the information processing unit. Currently, the most widespread are biosensors based on a silver chloride $\mathrm{Ag} / \mathrm{AgCl}$ electrode, which are metallic silver with a chloride layer deposited on its surface and operate in a hydrogel medium previously applied to a sensitive element . Distinctive features of such electrodes are stability of readings and low noise level [2]. The disadvantages of silver chloride electrodes include relatively high impedance values, and therefore a wet gel has to be applied to the skin. Silver iodide can be used to replace silver chloride. However, this compound has an undefined phase composition that can change during storage [3], which will lead to instability of the sensor readings. Therefore, the search for silver compounds with high ionic conductivity and applicable in biosensors is an urgent task.

In this work, a solid electrolyte with the composition of $\operatorname{Ag}_{16} \mathrm{I}_{12} \mathrm{P}_{2} \mathrm{O}_{7}$, which, according to the literature, have a high ionic conductivity with respect to silver ions was synthesized and its electrical properties were studied.

\section{Experimental}

The $\mathrm{Ag}_{16} \mathrm{I}_{12} \mathrm{P}_{2} \mathrm{O}_{7}$ compound is stable at low temperatures and incongruently melts at $554 \mathrm{~K}$, according to the phase diagram [4] presented in Fig. 1.

一 Corresponding author: ulikhin@solid.nsc.ru 


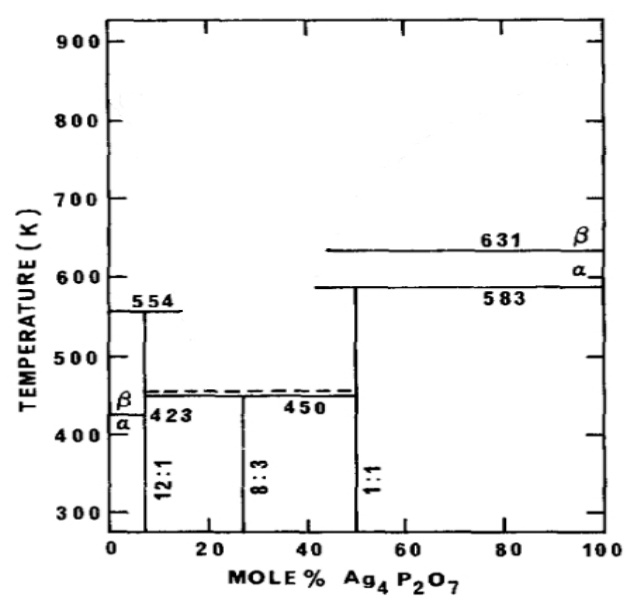

Fig. 1. The phase diagram of the system $\mathrm{AgI}-\mathrm{Ag}_{4} \mathrm{P}_{2} \mathrm{O}_{7}[4]$.

The synthesis was carried out by solid state technique from silver pyrophosphate $\mathrm{Ag}_{4} \mathrm{P}_{2} \mathrm{O}_{7}$ and silver iodide $\mathrm{AgI}$ in the conditions determined form the phase diagram. Accordingly, the synthesis temperature of the compound is was in the range of 450-554 K.

First, silver iodide was synthesized by deposition from water solutions according to the procedure described in [5] by reaction (1):

$$
\mathrm{AgNO}_{3}+\mathrm{KI}=\mathrm{AgI} \downarrow+\mathrm{KNO}_{3}
$$

Compound $\mathrm{Ag}_{4} \mathrm{P}_{2} \mathrm{O}_{7}$ was also obtained from $\mathrm{Na}_{4} \mathrm{P}_{2} \mathrm{O}_{7}$ and $\mathrm{AgNO}_{3}$ solutions by reaction (2):

$$
4 \mathrm{AgNO}_{3}+\mathrm{Na}_{4} \mathrm{P}_{2} \mathrm{O}_{7}=\mathrm{Ag}_{4} \mathrm{P}_{2} \mathrm{O}_{7} \downarrow+4 \mathrm{NaNO}_{3}
$$
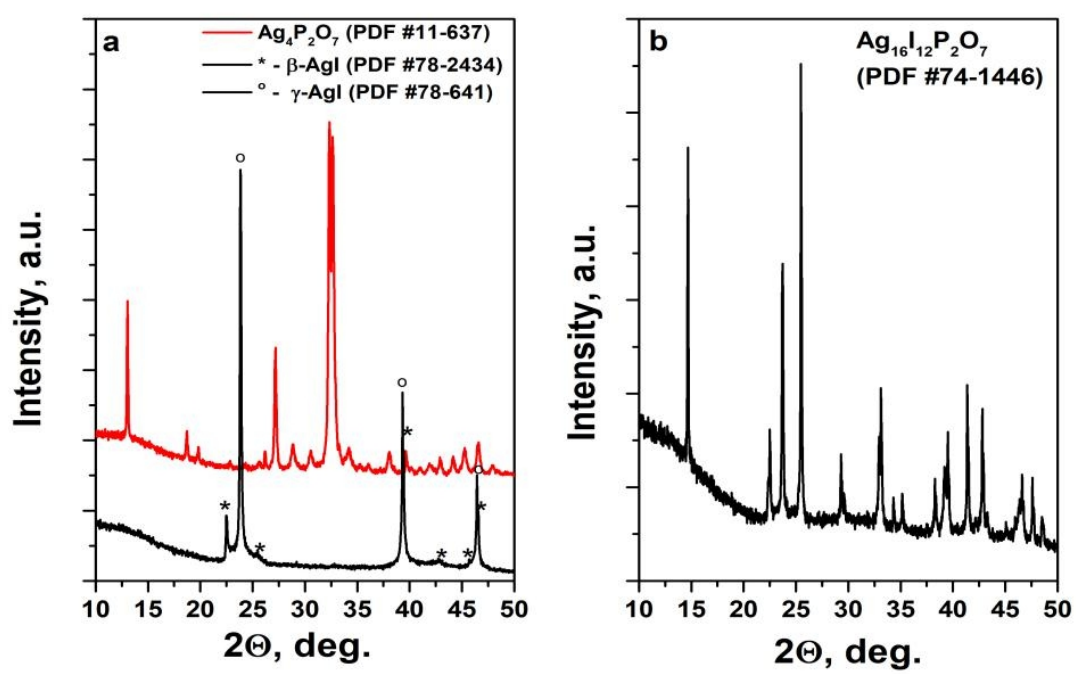

Fig. 2. X-Ray diffraction patterns of initial compound (a) and synthesized $\mathrm{Ag}_{16} \mathrm{I}_{12} \mathrm{P}_{2} \mathrm{O}_{7}$ (b). 
The phase composition of the synthesized compounds was controlled by X-ray phase analysis method using a Bruker D8 Advance diffractometer with $\mathrm{CuK}_{\mathrm{a}}$ radiation (Fig. 2a). The obtained silver iodide was a mixture of two phases: $\beta$-, and $\gamma$-AgI (PDF \# 78-2434 and PDF \# 78-641, respectively). The diffraction pattern of silver pyrophosphate $\mathrm{Ag}_{4} \mathrm{P}_{2} \mathrm{O}_{7}$ contains only the diffraction peaks corresponding to the pure compound (PDF \# 11-637).

The mixture of $\mathrm{AgI}$ and $\mathrm{Ag}_{2} \mathrm{P}_{2} \mathrm{O}_{7}$ components taken in a stoichiometric ratio 12:1 corresponding to the compound $\mathrm{Ag}_{16} \mathrm{I}_{12} \mathrm{P}_{2} \mathrm{O}_{7}$, was thoroughly mixed, heated up to $453 \mathrm{~K}$ and kept at this temperature for 48 hours. X-ray diffraction phase analysis of the obtained sample showed that the positions the diffraction peaks in the powder diffraction pattern correspond to the compound $\mathrm{Ag}_{16} \mathrm{I}_{12} \mathrm{P}_{2} \mathrm{O}_{7}$ PDF \#74-1446 (Fig. 2b), no reflections related to other phases were found.

The compound was pressed into pellets under a pressure of $200 \mathrm{MPa}$ with pressed-in silver electrodes. The pellets were installed in a measuring cell and conductance measurements were carried out in the temperature range of 213-373 K by complex impedance spectroscopy method in the frequency range of $1 \mathrm{~Hz}-1 \mathrm{MHz}$ using a Precision LCR Meter HP-4184A and a Zive SP2 electrochemical station.

\section{Results and Discussion}

Fig. 3 shows Nyquist plots at 213 and $330 \mathrm{~K}$ which may be fairly described in terms of the equivalent electrical circuit including elements corresponding to bulk impedance $\left(Z_{b}\right)$, grain boundary impedance $\left(\mathrm{Z}_{\mathrm{gb}}\right)$, electric double layer capacitance at grain boundaries $\left(\mathrm{C}_{\mathrm{gb}}\right)$, electrode impedance $\left(Z_{\mathrm{e}}\right)$ and geometric capacitance of the measuring cell $\left(\mathrm{C}_{\mathrm{c}}\right)$. The total impedance can be written as $Z=Z_{b}+Z_{g b}+Z_{e}$ according to this circuit. The values of $Z_{g b}$ and $Z_{\mathrm{e}}$ depend on the electric field frequency. Due to the fact that the investigated compound is a superionic conductor and the impedance contributions of the bulk and grain boundaries impedances are close, the contribution of grain boundaries impedance to the total conductivity can be distinguished only in the high-frequency region. The electrode impedance in the low-frequency region can be described by a constant phase element. The presence of a large contribution of electrode polarization indicates the prevailing ionic character of conductivity.
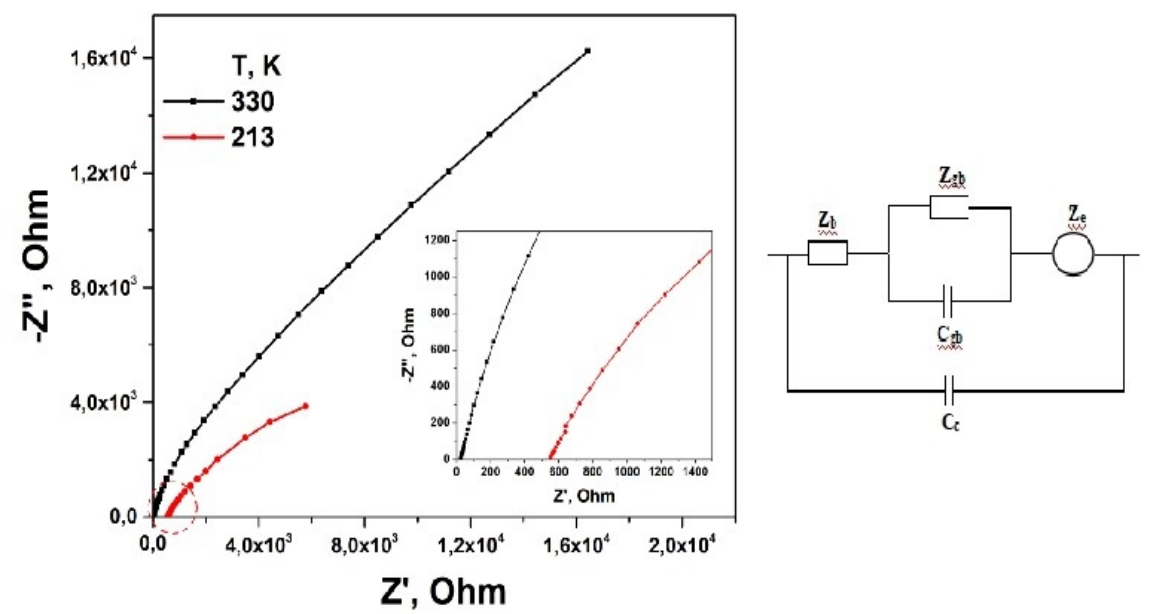

Fig. 3. Impedance hodographs of the test sample at $\mathrm{T}=213 \mathrm{~K}$ and $330 \mathrm{~K}$ and the equivalent electrical circuit. 


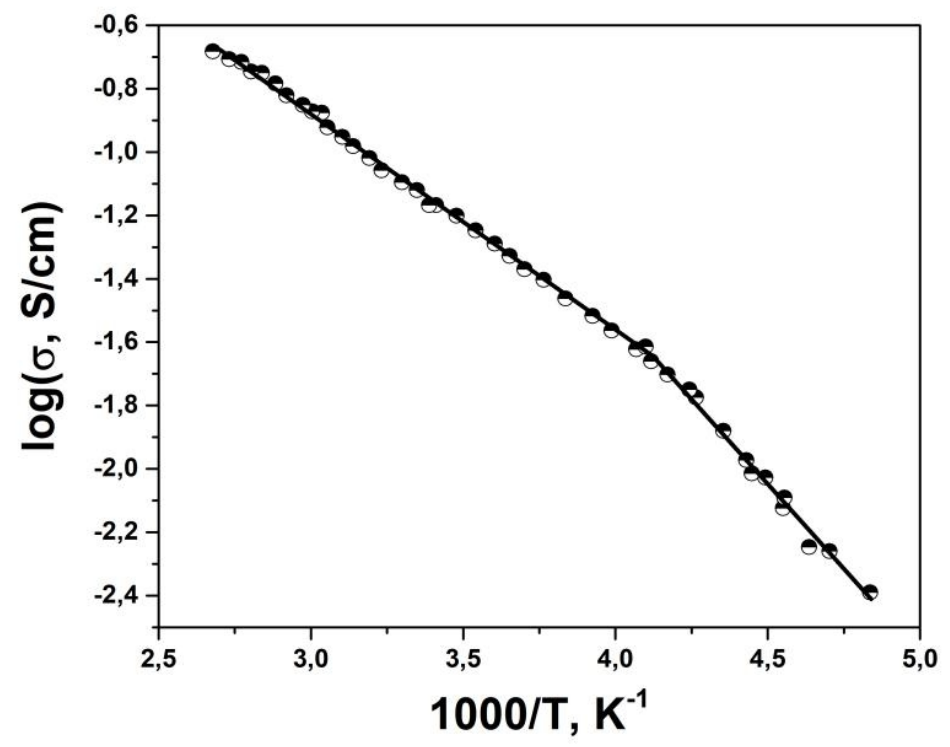

Fig. 4. The $\mathrm{Ag}_{16} \mathrm{I}_{12} \mathrm{P}_{2} \mathrm{O}_{7}$ thermal dependence of conductivity.

The temperature dependence of conductivity is shown in Fig 4. The bulk ionic conductivity values were calculated according to the above equivalent circuit at each temperature. The conductivity does not change linearly over the entire temperature range. At a temperature of $\sim 220 \mathrm{~K}$, an inflection is observed, accompanied by a decrease in the activation energy. Such conductivity behavior seems to be caused by the ordering of cations at low temperatures. Similar effects have been reported for other fast-ion electrolytes, such as polycrystalline $\mathrm{RbAg}_{4} \mathrm{I}_{5}$ [6] and $\mathrm{Ag}_{7} \mathrm{I}_{4} \mathrm{AsO}_{5}$ [7]. The total change in conductivity in the investigated temperature range is less than two orders of magnitude. The conductivity parameters are given in Table 1 . The results of the study of ionic conductivity by impedance spectroscopy showed that the compound $\mathrm{Ag}_{16} \mathrm{I}_{12} \mathrm{P}_{2} \mathrm{O}_{7}$ has a high ionic conductivity of about $10^{-1} \mathrm{~S} / \mathrm{cm}$ at room temperature, which is 3-4 orders of magnitude higher than the conductivity of silver iodide [8].

Table 1. The conductivity parameters of $\operatorname{Ag}_{16} \mathrm{I}_{12} \mathrm{P}_{2} \mathrm{O}_{7}$.

\begin{tabular}{c|c|c|c|c|c|c|}
\hline Parameters & $\boldsymbol{\sigma}_{213}, \mathbf{S} / \mathbf{c m}$ & $\boldsymbol{\sigma}_{273}, \mathbf{S} / \mathbf{c m}$ & $\boldsymbol{\sigma}_{373}, \mathbf{S} / \mathbf{c m}$ & $\mathbf{E}_{\text {akt }}{ }^{*}, \mathbf{e V}$ & $\mathbf{E}_{\text {akt }}{ }^{* *}, \mathbf{e V}$ \\
\hline Values & $4.10 \cdot 10^{-3}$ & $4.70 \cdot 10^{-2}$ & $2.15 \cdot 10^{-1}$ & $0.23 \pm 0.02$ & $0.16 \pm 0.02$ \\
${ }^{*} \mathrm{~T}=213-240 \mathrm{~K}$ \\
${ }^{* *} \mathrm{~T}=240-373 \mathrm{~K}$
\end{tabular}

One of the key parameters for biosensors is a high value of ionic conductivity, since this allows recording a high-quality signal with a minimum noise level in a wide frequency range. Biosensors are widely used today, as a rule, they are made on the basis of an $\mathrm{Ag} / \mathrm{AgCl}$ silver chloride electrode. However, the conductivity of silver chloride does not exceed $10^{-7} \mathrm{~S} / \mathrm{cm}$ at $\mathrm{T}=25^{\circ} \mathrm{C}$ [9], while the conductivity of $\operatorname{Ag}_{16} \mathrm{I}_{12} \mathrm{P}_{2} \mathrm{O}_{7}$ is $\sim 10^{-1} \mathrm{~S} / \mathrm{cm}$, which is 6 orders magnitude higher than the conductivity of silver chloride. 


\section{Conclusion}

Solid state technique allows one to obtain superionic solid electrolyte $\operatorname{Ag}_{16} \mathrm{I}_{12} \mathrm{P}_{2} \mathrm{O}_{7}$ with a high silver ionic conductivity about of $10^{-1} \mathrm{~S} / \mathrm{cm}$ at room temperature. This solid electrolyte will be used in ceramic cardiographic biosensors instead of silver halide salts.

The work was supported by the RFBR grant no. 18-29-11054mk.

\section{References}

1. X. An, G.K. Stylious, Materials 11, 25 (2018)

2. A. Albulbul, Bioengineering 3, 1 (2016)

3. N.F. Uvarov, E.F. Hairetdinov, Yu.T. Pavlyukhin, A.I. Rykov, Solid State Ionics 96, 233-237 (1997)

4. M. Sayer, S.L. Segel, J. Noad et al. J. Solid State Chem. 42, 191 (1982)

5. G. Brauer, Preparative Inorganic Chemistry Guide (M Izdatinlit, 1956)

6. S. Geller, Phys. Rev. B 14, 4345 (1976).

7. R. J. Grant, M.D. Ingram, L.D.S. Turner, C.A. Vincent, J.Phys. Chem. 82, 2838 (1978).

8. N. F. Uvarov, E. F. Hairetdinov, B. B. Bokhonov, N. B. Bratel, Solid State Ionics 8688, 573 (1996)

9. N. F. Uvarov, J. Maier, Solid State Ionics 61, 251 (1993) 